\title{
A UTILIDADE DA PESQUISA PARA O SERVIÇO SOCIAL
}

\author{
Potyara A. P. Pereira ${ }^{1}$
}

\section{RESUMO}

Este artigo trata da utilidade da pesquisa para o Serviço Social e da importância de torná-la uma atividade integral e intrínseca à profissão. Critica a persistência da dicotomia entre teoria e prática nos meios profissionais e a tradicional redução do Serviço Social a um conjunto de técnicas. Ao mesmo tempo em que aponta dificuldades de aplicação da pesquisa no dia-a-dia do assistente social, reconhece a existência de avanços investigativos na profissão e exorta os profissionais a encararem a pesquisa como uma necessidade científica e não um luxo intelectual.

PALAVRAS-CHAVE: Pesquisa; Serviço Social; Ciência.

\section{INTRODUÇÃO}

No Serviço Social existem questões que apesar de antigas e recorrentemente discutidas, ainda estão na ordem do dia exigindo reflexões. Uma delas é a questão da utilidade da pesquisa para a profissão e a possibilidade de torná-la uma atividade de uso corrente e sistemático no trabalho do assistente social.

Com efeito, por mais que tenhamos progredido no entendimento de que não há nenhum sentido em separar teoria de empiria, assim como academia de prática profissional, de vez em quando somos surpreendidos com argumentos que reafirmam essas inconcebíveis dicotomias, seguidos da automática e exclusiva identificação da pesquisa com a teoria e com a academia.

Esta é uma questão de peso - pela sua recorrência e disseminação entre a categoria - a ser decisivamente enfrentada pelos assistentes sociais e confrontada com o

\footnotetext{
${ }^{1}$ Professora do Departamento de Serviço Social da Universidade de Brasília (UnB) e Coordenadora do Núcleo de Estudos e Pesquisas em Política Social (NEPPOS), do Centro de Estudos Avançados Multidisciplinares (CEAM) da UnB.

Serviço Social \& Saúde Campinas

$\begin{array}{lll}\text { v. } 4 & \text { n. } 4 & \text { p. } 1-156\end{array}$

Maio 2005
} 
seguinte suposto básico: de que a pesquisa longe de ser um luxo intelectual é uma necessidade de realização conseqüente da profissão e condição de possibilidade de rupturas com atitudes e práticas voluntaristas, tópicas e impensadas. Isso porque a pesquisa é parte integral e intrínseca da profissão; por isso, não pode ser dispensada, sob pena de esvaziar o Serviço Social de pertinência científica e, portanto, de status de profissão de nível superior que se apóia em embasamento teórico nutrido por contínuas e sistemáticas investigações da realidade.

\section{DIFICULDADES DE APLICAÇÃO DA PESQUISA NO DIA-A-DIA DO EXERCÍCIO PROFISSIONAL}

Sabe-se que nas condições atuais de realização do Serviço Social, esse entendimento é de difícil aplicação por vários motivos.

Um deles refere-se à tradicional baixa produtividade em pesquisa no Serviço Social, em grande parte devido a um pecado original: o de supor que o Serviço Social é uma tecnologia e, como tal, não deve ocupar-se com processos mais elaborados de investigação científica.

Como dizia Greenwood (1970; 1973), professor da Universidade da Califórnia / Estados Unidos, nos anos 1960/70 - e mentor intelectual de vários assistentes sociais latino-americanos, incluindo brasileiros - a principal contribuição da pesquisa para o Serviço Social seria propiciar a construção de tipologias de diagnósticos e tratamento, mediante a conversão do conhecimento das Ciências Sociais em princípios para o exercício da prática profissional. Portanto, no seu ponto de vista, o Serviço Social, diferentemente das ciências, não estaria voltado para a "acurada descrição e interpretação do mundo social”, mas para o “controle desse mundo”, mediante o manejo de técnicas, informadas por outras disciplinas, tal como procedem, a seu ver, as tecnologias e as engenharias (1970, p.17; 1973, p.47). São dele as seguintes palavras: “O gênero tecnologia abrange todas as disciplinas que têm por objeto operar mudanças controladas nos relacionamentos naturais, através de procedimentos relativamente estandartizados [...]. Tradicionalmente faz-se uma distinção precisa, em função das matérias de que se ocupam, entre duas espécies deste

\begin{tabular}{llllll}
\hline Serviço Social \& Saúde & Campinas & v. 4 & n. 4 & p. 1-156 & Maio 2005
\end{tabular} 
gênero, ou seja, entre a engenharia e as práticas. Os tecnologistas que planejam materiais não humanos são chamados engenheiros; aqueles que se ocupam com seres humanos, são chamados de práticos, ainda que alguns entre estes últimos, ocasionalmente, sejam denominados como engenheiros humanos. Os assistentes sociais são uma variedade dentro destas últimas espécies” (1970, p. 16/17) [...] que, como tal, “não produzem conhecimento para contribuição à teoria científica. Seu sucesso depende de quão habilmente utilizam o que já é conhecido. Mesmo na prática mais orientada pela ciência, isto é, a medicina, o profissional típico não é um produtor mas um consumidor do conhecimento científico" (p.23).

Ou seja, o Assistente Social deveria exercer um controle das demandas e necessidades sociais com as quais cotidianamente se depara, mas sem a veleidade de elaborar um quadro explicativo próprio das mesmas e sem dispor de um instrumental metodológico particularizado. É como se a prática - especialmente a do assistente social fosse uma instância anti-intelectual (HOWE, 1987), que dispensasse processos de identificação do problema a ser enfrentado, de escolha do método a ser empregado, de estabelecimento dos objetivos a serem perseguidos, de reflexão científica, os quais, como sabemos, são sempre subsidiados por pesquisas guiadas por paradigmas, que podem variar de acordo com a visão de mundo adotada.

Mas, ironicamente, foi como uma instância anti-intelectual que a prática profissional passou a ser majoritariamente pensada - e até com certo orgulho - por consideráveis parcelas da categoria, porque ser prático, nos termos de Greenwood, converteu-se em virtude executiva, em sabedoria com os pés no chão, que impedia o assistente social de se meter em seara alheia e se enredar em elucubrações teóricas para as quais não estava preparado e lhes eram dispensáveis (HOWE, 1987). Portanto, “onde houver orientação científica disponível [acrescenta Greenwood, idem, p.23], ele [o assistente social] vale-se da mesma. Mas quando faltar essa orientação, ele preenche o vazio com a sua intuição”. Disso se conclui que se o assistente social não precisa de teoria, a teoria se distancia dele, deixando de ser assunto relevante para a profissão.

Não foi à toa que, nos anos 1960 e 70, uma discussão recorrente, especialmente no âmbito das Escolas, era a que procurava saber se o Serviço Social seria uma ciência,

\begin{tabular}{llllll}
\hline Serviço Social \& Saúde & Campinas & v. 4 & n. 4 & p. 1-156 & Maio 2005 \\
\hline
\end{tabular}


arte ou técnica, em torno da qual se perfilavam adesões ou resistências às concepções tecnicistas da profissão. Porém, além disso, já nos anos 1960, resistências mais organizadas e conscientes da importância de se eleger um paradigma crítico, referenciado no marxismo, inauguraram uma tendência favorável a valorização da pesquisa e da teoria no Serviço Social. E isso não aconteceu apenas na América Latina. Nessa mesma época, é possível identificar tendência semelhante nos Estados Unidos, Canadá e Inglaterra, no bojo do que passou a ser conhecido como Serviço Social Radical - uma vertente alternativa à visão conservadora da profissão, ancorada na crítica socialista da sociedade e das instituições capitalistas (GALPER, 1980).

Entretanto, apesar desses avanços, o tecnicismo exerceu influência duradoura no Serviço Social. Nos anos 1980 vários depoimentos recolhidos na literatura especializada brasileira informam que a situação da pesquisa nessa área de conhecimento era catastrófica, porque sufocada pelo pragmatismo, pela precária formação universitária e pela falta de curiosidade científica dos assistentes sociais (FALEIROS, 1986; IAMAMOTO,1987). E relacionadas a essas atitudes ressaltava-se a falta de espírito crítico da maioria dos profissionais e a existência da velha, mas ainda atual, dicotomia entre teoria e prática no desempenho da profissão.

Hoje o panorama é mais alentador - embora não de todo satisfatório - pois houve mudança positiva não só do ponto de vista da quantidade, mas da qualidade da pesquisa, graças à melhoria de condições materiais, institucionais, organizativas, financeiras e intelectuais, necessárias à maioridade investigativa da profissão. E entre as condições favoráveis a essa mudança cabe ressaltar a criação e ampliação dos cursos de pós-graduação stricto sensu (mestrado e doutorado); o reconhecimento e presença da profissão nas agências oficiais de fomento à pesquisa; a formação de núcleos de pesquisa dentro das Universidades; os intercâmbios nacionais e internacionais e o processo de redemocratização do país, em 1985, após vinte e cinco anos de ditadura, pois sem democracia não haveria condições de se expandir a pesquisa e nem de realizá-la de forma relativamente autônoma.

Como diz José Paulo Netto (1996), os assistentes sociais vêm assumindo certa maturidade no domínio da elaboração teórica e mantendo interlocução com outras áreas de

\begin{tabular}{llllll}
\hline Serviço Social \& Saúde & Campinas & v. 4 & n. 4 & p. 1-156 & Maio 2005 \\
\hline
\end{tabular}


conhecimento mais consolidadas, o que constitui, sem dúvida, um caminho promissor para o adensamento teórico do Serviço Social. Mas, por outro lado, ao resistirem, desde os anos 1970, ao fascínio do pensamento pós-moderno, muitos assistentes sociais pesquisadores ficaram desfalcados de antigas interlocuções nas Ciências Sociais que aderiram a esse pensamento, tendo, portanto, conforme Lessa (2000, p. 35), de desenvolverem investigações de fundo de que necessitam. E isso, contraditoriamente, levou a um maior agendamento da pesquisa no Serviço Social.

Um outro motivo da difícil aplicação do entendimento de que a pesquisa é parte integral e intrínseca do exercício da profissão, tem a ver com a atual revalorização do enfoque pragmático no enfrentamento das necessidades sociais e dos novos riscos sociais típicos da época contemporânea. Essa revalorização se deu na razão direta da desvalorização da teoria, ou das grandes narrativas, patrocinadas pelo discurso pósmoderno, niilista e avesso ao pensamento crítico, que guarda forte afinidade com o caráter tecnocrático do modelo sócio-econômico neoliberal dominante desde os anos 1970.

Assim, se áreas de conhecimento tradicionalmente reconhecidas como interpretações teóricas abrangentes da vida social encontram-se, como as Ciências Sociais, em estado de "mal-estar na teoria e com a teoria”, conforme Borón (2001, p. 358), o que dizer do Serviço Social que, por vontade própria, nunca chegou a formar uma tradição teórica? Que condições intelectuais e políticas concretas o Serviço Social tem para se contrapor ao clima ideológico atual dominado pelo imediatismo, relativismo e pelas leituras da realidade desgarradas de "circunstâncias históricas, fatores estruturais ou tradições culturais” (BORON: idem, p.360), que dispensam a pesquisa em profundidade? Como não sucumbir ao rolo compressor do pensamento único e da pressão pragmática de reduzir o assistente social a mero técnico, como entendia Greenwood, ou a um difuso gestor social, sem particularidades profissionais e competências diferenciadas, e cuja principal função é zelar pela eficiência e eficácia de ações que lhe são institucionalmente confiadas?

\section{VISÕES EQUIVOCADAS E URGÊNCIA DE CONTRAPONTOS}

Tais questionamentos indicam uma tendência que, sob a égide da pósmodernidade e da tecnocracia neoliberal, tende a encarar o Serviço Social como:

\begin{tabular}{llllll}
\hline Serviço Social \& Saúde & Campinas & v. 4 & n. 4 & p. 1-156 & Maio 2005
\end{tabular}


a) um campo de atividade e não uma disciplina dotada de um puzzle ou um quebra-cabeça central que exigiria esforços investigativos mais complexos e metodologias apropriadas ao seu desvendamento;

b) uma atividade essencialmente prescritiva e, portanto, somente preocupada com a intervenção ou a eficiente prestação de serviços baseada na hoje supervalorizada relação entre custo e benefício.

Mas essa tendência obviamente não condiz com o atual projeto de profissão e nem com os atuais postulados teórico-metodológicos abraçados pelo Serviço Social brasileiro, que não quer mais abrir mão de procurar interpretar com maior rigor possível a realidade para nela atuar de forma esclarecida. Por isso, a radical recusa dessa tendência bem como das premissas baseadas no empirismo positivista que induzem até hoje o assistente social a estabelecer dicotomias incabíveis no seu exercício profissional, configura a principal atitude a ser adotada pela categoria.

Em vista disso, alguns contrapontos precisam ser urgentemente estabelecidos, abarcando várias frentes: a formação profissional; a ratificação do paradigma alternativo tanto ao empirismo positivista, ainda influente, quanto à atual onda pós-modernista que atinge a profissão; e o caráter e a função da pesquisa e da teoria em consonância com o paradigma a ser ratificado.

\section{CONTRAPONTOS NO ÂMBITO DA FORMAÇÃO PROFISSIONAL}

No que tange à formação profissional, deve ficar claro que esta é um processo que não se resume à garantia de competências intelectuais e operativas ao corpo discente, pois também deve visar à formação de atores sociais. Em outras palavras isso quer dizer que a formação do assistente social só será qualitativamente relevante se - parafraseando José de Sousa Martins (1978) - os Cursos de Serviço Social se transformarem em fontes criadoras de tipos humanos que, além da capacidade de compreenderem adequadamente a realidade e atenderem eficientemente aos reclamos sociais a eles dirigidos, "possam estabelecer compromisso indiscutível com valores que transcendem mecanismos internos de sustentação deste ou daquele sistema” (MARTINS, id.pp.33/33). Sendo assim, há que se fazer distinção entre formação, cujo objetivo é gerar profissionais “capazes de criar

\begin{tabular}{llllll}
\hline Serviço Social \& Saúde & Campinas & v. 4 & n. 4 & p. 1-156 & Maio 2005 \\
\hline
\end{tabular}


além das restritas ou nulas possibilidades de inovação dadas pelos papéis profissionais já existentes” (idem, pp. 33) e adestramento, de acordo com o qual os Cursos de Serviço Social seriam moldados pelas demandas do mercado e por imperativos dos blocos no poder. Ou seja, se guiados pelos propósitos da formação, os Cursos de Serviço Social se identificarão com os objetivos e sentidos originais de uma universidade que são os de desenvolver funções criadoras por meio de seus diplomados; mas, se guiados pelo adestramento, tais Cursos assumirão a feição de treinamentos técnicos ajustados a fins definidos externamente e sem a sua participação (ibidem).

Isso trás à tona a velha, mas ainda necessária discussão sobre a relação entre a universidade e o mercado de trabalho e, portanto, a reflexão sobre quem teria a preponderância na orientação dos rumos e das tendências da formação profissional: se as demandas utilitaristas desse mercado ou os princípios éticos, políticos e cívicos de uma universidade voltada par a criação, a produção do conhecimento e a autonomia de pensamento (PEREIRA-PEREIRA, 2003).

É certo que a opção pela preponderância dos objetivos da universidade tem que estar ciente da magnitude do problema que terá de enfrentar, pois o ensino da pesquisa e da teoria vem sofrendo em todas as áreas de conhecimento progressiva marginalização, em decorrência dos seguintes fatores (BORON, 2001, p.358/9):

a) crise da universidade como "contexto institucional no qual se realizam as tarefas de ensino, aprendizagem e pesquisa”;

b) ingerência crescente de instituições não acadêmicas, como o Banco Mundial, o Fundo Monetário Internacional, os governos e fundações privadas na elaboração da agenda de pesquisas sociais e econômicas e no seu financiamento, especialmente no chamado Terceiro Mundo;

d) prevalência do saber anti-teórico fortalecido pelas pressões do mercado e de importantes fontes de financiamento por respostas imediatas, pragmáticas e não questionadoras;

e) transformação dos profissionais em técnicos permanentemente ocupados em gerir seletivamente a miséria em nome de uma pretensa distribuição justa de recursos escassos; e

\begin{tabular}{llllll}
\hline Serviço Social \& Saúde & Campinas & v. 4 & n. 4 & p. 1-156 & Maio 2005 \\
\hline
\end{tabular}


orçamentos insuficientes, salários baixos e precária infra-estrutura, impeditivos de produções científicas de qualidade.

f) privatização crescente da educação em todos os níveis.

\section{CONTRAPONTOS REFERENTES AO PARADIGMA ALTERNATIVO}

Quanto à eleição de um paradigma alternativo, sua importância deve-se ao reconhecimento de que o modelo de ciência que se fundamentava em dualismos entre homem e natureza, matéria e espírito, teoria e prática, sujeito e objeto, e que fragmentava o campo do conhecimento social em disciplinas independentes e compartimentadas, padece de artificialismos que devem ser reexaminados. Contra o dualismo deve-se adotar a categoria contradição como a chave da compreensão relacional da realidade. Mas não só o dualismo como herança de um paradigma positivista que já encontrou seus limites, deve ser rechaçado. O pós-modernismo a ele associado, com sua fluidez analítica, sua visão caleidoscópica do mundo e seus exacerbados relativismo e pragmatismo, deve ser recusado. Em seu lugar há que se eleger um outro paradigma cuja postura teórica e metodológica reconheça que:

a) há unidade concreta do todo, que é dialeticamente contraditório, e não integradamente holístico ou confusamente caleidoscópico;

b) perceba diferenças entre realidade e fantasia;

c) não seja expressão de uma cosmovisão conservadora e nem queira recriar o mundo à imagem e semelhança dos poderes estabelecidos;

d) não encare como natural a desigualdade social e se constitua em pressuposto de pesquisas e políticas que se coloquem a serviço das necessidades humanas e não do capital.

Esse paradigma já foi adotado pelo Serviço Social brasileiro e é conhecido pelo nome de materialismo histórico - o único capaz de habilitar o pesquisador a descobrir as condições ideologicamente encobertas da atual barbárie social e a reconstruir teoricamente contrapontos aos mitos positivistas e pós-modernos ainda em voga.

Além disso, é esse paradigma que permitirá livrar o Serviço Social da torturante busca por uma especificidade, que acaba cada vez mais estreitando o seu campo cognitivo e

\begin{tabular}{llllll}
\hline Serviço Social \& Saúde & Campinas & v. 4 & n. 4 & p. 1-156 & Maio 2005 \\
\hline
\end{tabular}


o isolando do conjunto da teoria social mais ampla. É com base nesse paradigma que o assistente social pode entender que a identidade da profissão não se dá pela seleção de propriedades ou mesmo fatias da realidade que lhe sejam únicos e singulares, mas por formas particulares de ser e de agir, a serem compartilhadas com outros ramos do saber. Desse modo, fica entendido que não existem especificidades no Serviço Social e nem em qualquer outra disciplina científica, mas formas particulares de relação dessas disciplinas com a realidade. Portanto, o saber profissional longe de ser uma singularidade, integra de fato uma unidade de conhecimento e ação compartilhada e disputada com outras áreas de conhecimento, que só no âmbito corporativo da divisão do trabalho - de ranço positivista é passível de recortes excludentes.

Tais argumentos não sugerem que os assistentes sociais deixem de se preocupar em definir atributos que confiram particularidade à profissão. Mas essa preocupação não deve excluir o Serviço Social de um legado filosófico e científico que, por ser geral, também lhe pertence. Assim, se os assistentes sociais se vêm instados a trabalhar com categorias ou conceitos gerais, que refletem aspectos, propriedades, movimentos e relações que lhe dizem respeito, ele não pode abrir mão deles pelo fato de não serem de seu uso exclusivo. Portanto, o Serviço Social também tem que se pautar pela lógica do conhecimento, que é geral, e beber na fonte das teorias sociais para a qual ele e as demais áreas de conhecimento podem e devem contribuir com os seus achados particulares (Pereira-pereira, 2003; 1988). Isso é diferente da postura de mera conversão de princípios dessa teoria à prática profissional, sugerida por Greenwood.

Daí porque a particularidade do Serviço Social não deve ser definida por critérios legais, estatutários ou formais, mas pelo tipo de relação que o profissional mantém com fatos e processos reais colocados historicamente à sua compreensão e ação.

\section{CONTRAPONTOS REFERENTES AO CARÁTER E À FUNÇÃO DA PESQUISA E DA TEORIA}

Por fim, no que concerne ao caráter e à função da pesquisa e da teoria no Serviço Social, em consonância com o paradigma indicado, faz-se necessário explicitar que existem pesquisas e pesquisas. Ou melhor, existem investigações com o objetivo de testar teorias,

\begin{tabular}{llllll}
\hline Serviço Social \& Saúde & Campinas & v. 4 & n. 4 & p. 1-156 & Maio 2005
\end{tabular}


produzir novos conhecimentos ou fazer avançar os quadros conceituais existentes, os modelos analíticos disponíveis e seus dispositivos metodológicos, referentes a um determinado campo do saber; mas também existem outras investigações menos complexas, embora não menos importantes, como as que são realizadas para resolver problemas práticos ou particulares. Neste caso, “o pesquisador está, apenas, interessado em descobrir a resposta para um problema específico ou descrever um fenômeno da melhor forma possível” (RICHARDSON:1999, p.17) - o que condiz com o trabalho de muitos assistentes sociais.

Isso reforça a idéia já enunciada de que a pesquisa não é privilégio de poucos ou uma fórmula precisa que, aplicada corretamente, conduzirá sempre à descoberta da verdade. Mas também não é uma atividade banal que dispense aprendizagens e requerimentos subjetivos como autenticidade, curiosidade e rigor investigativo (QUIVY \& CAMPENHOUDT: 1998), aos quais se deve acrescentar o propósito de ruptura com preconceitos e falsas evidências e de contribuir para a satisfação de legítimas necessidades sociais. Em outras palavras isso quer dizer que, para se fazer pesquisa e com ela obter conhecimento, precisa-se de quadros teóricos e metodológicos explícitos, associados à tarefa de observação dos fatos concretos. Além disso, deve haver uma procura autêntica e sincera da verdade, movida pela curiosidade de conhecê-la em proveito da atuação profissional responsável. "Não a verdade absoluta, estabelecida de uma vez por todas pelos dogmas, mas aquela que se repõe sempre em questão e se aprofunda incessantemente devido ao desejo de compreender com mais justeza a realidade em que vivemos e para cuja produção contribuímos” (QUIVY \& CAMPENHOULDT: id., p.24).

\section{ARREMATES}

Essas exortações podem parecer utópicas se considerarmos as dificuldades a serem enfrentadas por quem atualmente deseje realizar um trabalho crítico e propositivo. Entretanto, nunca é demais lembrar que as utopias fazem parte da realidade e que elas podem configurar um projeto possível desde que abraçado, de imediato, por atores sociais e não por meros técnicos. Em adição, convém reconhecer que o exercício profissional do assistente social - seja em instituições ou fora delas - é uma fonte fecunda de informações

\begin{tabular}{llllll}
\hline Serviço Social \& Saúde & Campinas & v. 4 & n. 4 & p. 1-156 & Maio 2005 \\
\hline
\end{tabular}


que, no mínimo, podem sofrer tratamento analítico de primeira aproximação e subsidiar patamares mais elaborados de análises com a participação de outros sujeitos. Este é um processo que, além de não ser isolado e unidisciplinar, exige um empenho constante do profissional de constantemente colher informações do seu cotidiano de trabalho, analisá-las como suporte às decisões a serem tomadas, discuti-las com seus pares e realizar tentativamente a síntese teórica de seus achados. Vale dizer: é só pela investigação que se poderá conhecer, com clareza, as possibilidades e os limites da intervenção, bem como o sentido que deverá ser dado a novas investigações. Isso porque:

a) a investigação não é uma atividade antagônica à intervenção. Se esse antagonismo ocorre, é devido a deformações profissionais que precisam ser urgentemente superadas, pois, sem investigação a intervenção torna-se cega e sem intervenção a investigação torna-se inútil;

b) a prática não corresponde a uma ação mecânica e intuitiva. Como forma de ação pensada, não impõe fronteiras entre atividade material e intelectual e representa um conjunto de atividades, inclusive a teórica.

É, pois na unidade entre teoria - prática e investigação - intervenção que o Serviço Social poderá encontrar a via alternativa, de sentido dialético, que o tornará mais crítico e enriquecedor (PEREIRA-PEREIRA, 1988).

\begin{abstract}
This article deals with the usefulness of the research to Social Work, and the importance to make it an integral and intrinsic activity to the profession. It criticizes the persistence on the dichotomy between theory and practice in the professional ways and the traditional reduction of Social Work into a mere body of techniques. At the same time it shows difficulties of the application of research in the routine of social workers, it recognizes the existence of investigatory advancements in the profession and exhorts the professionals to consider the research as a scientific need and not as an intellectual superfluity.
\end{abstract}

KEY-WORDS: Research; Social Work; Science.

\begin{tabular}{llllll}
\hline Serviço Social \& Saúde & Campinas & v. 4 & n. 4 & p. 1-156 & Maio 2005
\end{tabular} 


\section{REFERÊNCIAS BIBLIOGRÁFICAS}

BORÓN, A. A coruja de Minerva: mercado contra democracia no capitalismo contemporâneo. Petrópolis: Vozes, 2001.

FALEIROS, V. Alternativas metodológicas da pesquisa em Serviço Social. In: Rev. Serviço Social \& Sociedade n ${ }^{0}$ 21. São Paulo: Cortez. Ano VII. Ago. 1986.

GREENWOOD, E. A Ciência Social e o Serviço Social: uma teoria de seu relacionamento. PUC/SP, 1970.

Metodologia de la investigación social. Buenos Aires: Paidós, 1773.

GALPER, Jeffry. Política social \& trabalho social. São Paulo: Cortez,1986.

HOWE, D. An introductión to social work theory. England: Ashgate, 1992.

IAMAMOTO, M. Questões preliminares postas pelos dados obtidos junto às unidades de ensino: tendências e alternativas. Relatório preliminar de pesquisa. ABESS/PUC-SP, setembro/1987.

LESSA, S. Serviço e trabalho: do que se trata? In: Revista Temporalis, Brasília: ABEPSS, n. 2. Ano I, Julho a dezembro 2000.

MARTINS, J.S. Sobre o modo capitalista de pensar. São Paulo: Hucitec, 1978.

NETTO, J. P. Transformações societárias e Serviço Social: notas para uma análise prospectiva da profissão no Brasil. In: Revista Serviço Social \& Sociedade, São Paulo: Cortez, n. 50. Ano XVIII, abr. 1996.

PEREIRA-PEREIRA, P. A. A importância da pesquisa para o desenvolvimento do Serviço Social no Brasil. In: Caderno técnico, Brasília: SESI, n. 17, 1988.

A formação do assistente social e o exercício profissional: a questão da militância intelectual e da criação de atores sociais. Brasília: 2003. Mimeografado.

RICHARDSON, R.J. Pesquisa social: métodos e técnicas. São Paulo: Atlas, 1999.

QUIVY, R \& CAMPENHOUDT, L. Manual de investigação em Ciências Sociais: trajectos. Lisboa: Gradiva, 1998.

\begin{tabular}{llllll}
\hline Serviço Social \& Saúde & Campinas & v. 4 & n. 4 & p. 1-156 & Maio 2005
\end{tabular} 